\title{
Rhythmic growth and age estimation of aerial roots in Dracaena draco (Asparagaceae)
}

\author{
Joanna Jura-Morawiec ${ }^{1}$ \\ Received: 5 February 2019 / Accepted: 31 May 2019 / Published online: 8 June 2019 \\ (c) The Author(s) 2019
}

\begin{abstract}
Key message Aerial roots (AR) of $D$. draco undergo periodic elongation, and growth units are distinguishable on its surface that allow the retrospective estimation of AR age.

Abstract Morphological changes in trees with age help understanding their growth patterns and developmental dynamics. Here, I studied Dracaena draco, a monocotyledonous tree, popularly cultivated in frost-free climates, but vulnerable in the wild. Its typical form becomes modified under stress conditions, forming numerous aerial, adventitious roots (AR) of unclear function. This study aimed to characterize both AR growth pattern and morphology relative to weather conditions. For this, the morphology and elongation rate of 25 AR from five dragon trees (ca 30-40 years old) growing outdoors at the Jardín Botánico Canario on Gran Canaria were recorded periodically over a 10 month period, encompassing both dry and wet seasons. AR growth was rhythmic, i.e., with alternating elongation and dormant phases that were easily distinguished morphologically. The maximum extension growth occurred during the months with the greatest rainfall totals for the study area. Extension growth varied from $1 \mathrm{~cm}$ to $7.3 \mathrm{~cm}$ with the mean $2.9( \pm 1.56) \mathrm{cm}$. Successive elongation of AR appeared on the surface as growth units delimited by remains of protective tissue broken by the AR tip resuming the growth. This morphological marker of rhythmic elongation, combined with precipitation, allows the retrospective estimation of AR age. Furthermore, this information enables to estimate when stress-induced AR formation occurred and thus, help to identity the cause of stress. This study is the first report of visual markers of seasonal growth in evergreen $D$. draco.
\end{abstract}

Keywords Active and dormant phases $\cdot$ Dragon trees $\cdot$ Monocotyledons $\cdot$ Morphology $\cdot$ Periodic growth

\section{Introduction}

Following the morphology of a tree as it changes relative to time helps to understand its growth pattern and its developmental dynamics. Macroscopic aspects of growth, such as leaf formation, branching, flowering, etc., provide information concerning the plant's pattern of growth, and this can be considered both at the whole plant level and at the organ level, e.g., leaf growth. A study of tree form can be conducted either by directly monitoring plant growth over a long period, or indirectly by its reconstruction based on

Communicated by H. Gärtner.

Joanna Jura-Morawiec

j.jura@gazeta.pl

1 Polish Academy of Sciences Botanical Garden-Centre for Biological Diversity Conservation in Powsin, Prawdziwka 2, 02-973 Warsaw, Poland analysis of morphological or anatomical markers that can be interpolated as the functional history of the meristem (Fritts 1976; Hallé et al. 1978; Barthélémy and Caraglio 2007). For example, rhythmic growth, i.e., alternation of dormant and active phases of the apical shoot meristem, may become marked on the shoot surface by cataphylls or internodes. Consequently, the stem becomes divided into growth units, i.e., units developed during an uninterrupted period of organ extension (Hallé and Martin 1968). These morphological units can be also referred to as metamers (Barlow 1994). Their length and number allow us to reconstruct, retrospectively, plant growth and also to estimate the age of the plant or of an organ. In referring to the plant's pattern of growth, what we are in fact considering is its architectural model (Hallé et al. 1978), which is genetically determined, but subject to the influences of the environment.

This investigation concerns growth pattern of Dracaena draco (Asparagaceae), a tree monocot endemic to the Canary Islands, Cape Verde, Madeira and Morocco (Marrero 
et al. 1998), but also commonly cultivated in different parts of the world as an ornamental. Regular and aberrant growth forms of D. draco can be distinguished (Beyhl 2001). The regular growth form has a single trunk and an umbrella-like crown bearing the leaves on the tips of the branches (Beyhl 1995). It follows the architectural model of Leeuwenberg (Hallé et al. 1978), like some dicotyledonous arborescent species of Senecio (Asteraceae) and Euphorbia (Euphorbiaceae). Crown development is subject to a certain rhythm. Branching of the trunk is correlated with flowering; thus, more than one equivalent axis is newly formed below the inflorescence which terminates the axis, and these subsequently repeat the construction of the parent axis (Symon 1974; Hallé et al. 1978; Bos 1984). Thus, the dragon tree crown consists of repetitive units/modules that arise at long time intervals (Symon 1974; Krawczyszyn and Krawczyszyn 2016). Data relating to the time of flowering, followed by branching, are divergent. For example, Symon (1974) noted that it occurs about every 10 years, while Byström (1960) reported that it can take place every 10-14 years. According to Krawczyszyn and Krawczyszyn (2016), the timing of flowering of a given branch is determined by the amount of sunlight it receives, with branches exposed to the sun flowering sooner than those subjected to shade. The orders of branching and frequency of flowering can be used as the basis for calculating the age of a dragon tree (Adolt and Pavlis 2004; Adolt et al. 2012); the oldest representative of $D$. draco, which grows on Tenerife (Canary Islands), is estimated to be about 400 years old (Mägdefrau 1975). The subterranean part of this species comprises an extended root system. Roots of Dracaena species undergo secondary growth, and are unique among monocots in this respect (Cheadle 1937; Carlquist 2012).

Aberrant growth forms of $D$. draco may differ in the shape of the crown and in height of the trunk (Beyhl 2001), with sunlight being indicated as a key factor in determining form (Krawczyszyn and Krawczyszyn 2016). Modification or distortion of the regular growth form may also results from the development of additional organs, such as aerial roots (AR) that usually hang off the branches or add to the volume of the trunk (Krawczyszyn and Krawczyszyn 2014). The function of AR in D. draco is not clear, but based on their large numbers, it is reasonable to assume that they are important to plant survival under stress conditions. It is supposed that they absorb water from the atmosphere and are initiated in response to water stress or damage (Lyons 1974; Krawczyszyn and Krawczyszyn 2014). Little is known about development and growth of these organs in D. draco. The aim of this present study is to characterize the pattern of AR extension and AR morphology relative to weather conditions. To address this point, I followed the AR growth and AR morphology of $D$. draco over a period of 10 months, encompassing dry and wet seasons, and this paper presents a study of dynamic AR elongation, during which their rhythmic growth was recorded and characterized.

\section{Materials and methods}

The subjects of the study were $D$. draco plants growing outdoors at the Jardín Botánico Canario "Viera y Clavijo" on Gran Canaria, Spain. This botanical garden is situated in Gran Canaria's isoclimate zone, referred to as dry and stepparic, between 200 and $500 \mathrm{~m}$ altitude, with $500 \mathrm{~mm} /$ year of rainfall (Montoya-Alonso et al. 2010), which corresponds with that of the natural habitat of $D$. draco (Marrero et al. 1998). Five D. draco plants of similar age (30-40 years), with trunk girth $105-130 \mathrm{~cm}$ at breast height, and having a mass of AR that hang mainly from the basal part of the crown, were chosen for investigations. Temporal changes to their morphology were followed, and for detailed analysis, 25 free-hanging, positively gravitropic, AR were chosen randomly, 5 per plant. AR length was measured from its tip to the point of attachment to the branch. Data were collected for morphology and change in AR length between November 2017 and August 2018, at four intervals, i.e., namely 21 st of November, 30th of January, 15th of May and 14th of August, so as to include both dry and wet seasons. Maximum rainfall occurred from December 2017 to February 2018. Precipitation and temperature data (see Fig. 1) were obtained from the Agencia Estatal de Meteorología (AEMET). Based on AR measurements, descriptive statistics (mean, standard deviation, maximum and minimum) were calculated using MS Excel. Photographs of AR were taken with a Nikon D3000 camera.

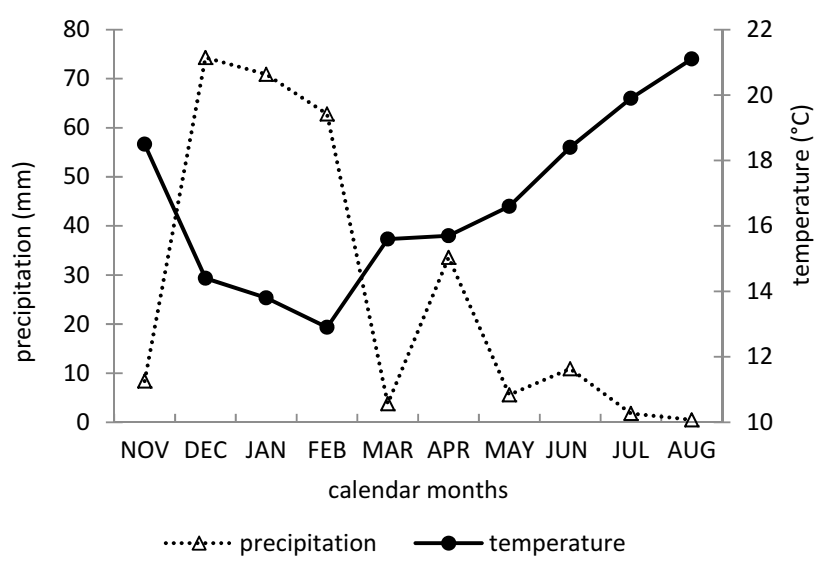

Fig. 1 Total monthly precipitation and the monthly average temperature at the Jardín Botánico Canario, November 2017-August 2018 


\section{Results and discussion}

\section{AR morphology}

The AR of a dragon tree show consecutive phases of elongation and rest in activity of the apical meristem, both easily distinguished at morphological level. The resuming of the capacity to grow by AR is associated with the appearance of a pale-yellow root-tip (Fig. 2a). Macroscopically, the newly formed part of the AR is green (Fig. 2b). When inactive (at dormant phase), the surface of the AR becomes gray-brown, whereas the tip is reddish-brown (Fig. 2c). Changes in pigmentation of the peripheral tissues, depending on the activity of the apical meristem, have also been observed for the AR of other species, such as Ficus microcarpa (Pryor and Wei 2015; Liu et al. 2016) and Philodendron lacerum (Mathews et al. 1997). Alternate periods of dormancy and active extension express themselves as rhythmic growth of the organ (Hallé et al.
1978), which helps the plant to withstand changes in temperature, water or nutrient availability.

Rhythmic (periodic) growth of the AR of D. draco is usually also reflected by changes to the AR surface. Here, collar-like thickenings appear which represent the remains of the tissue that protects the cup-shaped root-tip during the dormant phase. On resuming growth, this tissue is ruptured, thus marking the border of the previous extension (Fig. 2d). As a result, the surface of the AR becomes divided into growth units that resemble superficially stem's internodes. Sometimes the root-cap portion of the AR remains preserved and becomes pushed back alongside the growing tip of the AR (Fig. 2a-c). It seems reasonable to assume that it happens when the tip of AR starts to grow asymmetrically. The direction of AR growth may be determined by, e.g., light or gravity (Bellini et al. 2014). Morphological markers of rhythmic extension have been identified for AR of Pandanus spp. as "a distinct articulation in the surface texture of the root" (Gill and Tomlinson 1975). Fisher and Jayachandran (2000) also described dark, regular, surface rings that
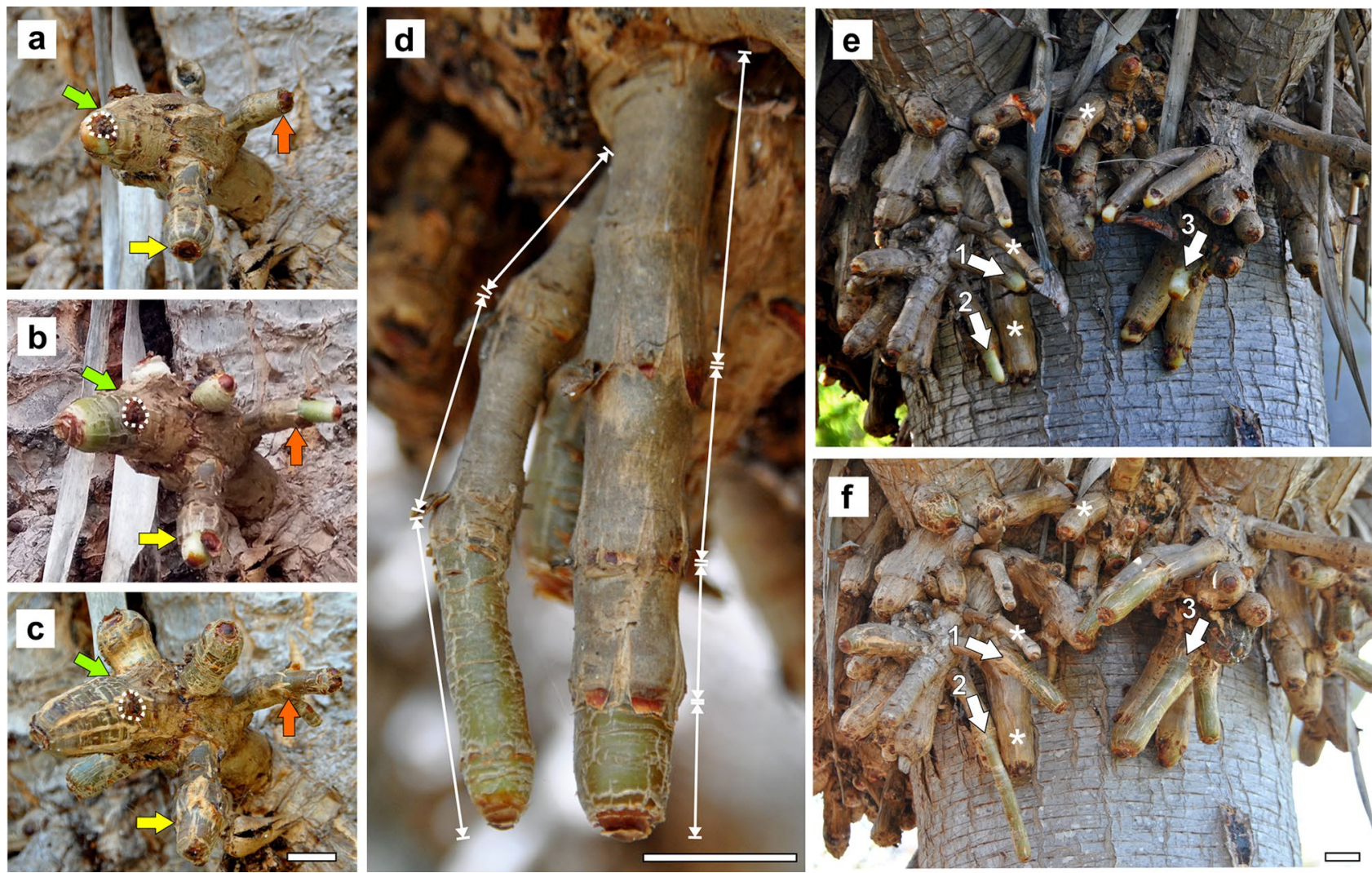

Fig. 2 Morphological markers of rhythmic elongation of AR of D. draco. a-c Successive stages in growth unit and cluster formation (AR view from January, May and August 2018, respectively). The initial length of three AR is marked with colored arrows; note the changes in pigmentation at the tips of $\mathrm{AR}$ when growth resumes $\mathbf{a}, \mathbf{b}$ and ceases $\mathbf{c}$. The dotted line points the position of the root-cap covering the tip of the AR that resumed growth. d Successive growth units (white lines) as determined a posteriori from the remains of the tissue that protects the root-tip; note the difference in length of growth units and the difference in pigmentation between the root-tip and the remainder of the AR. e, $\mathbf{f}$ Aggregation of AR at the base of the crown, as seen in January 2018 (e) and in May 2018 (f); changes in length of selected AR (no 1-3) are indicated by arrows, and examples of those in dormant phase by an asterisk. Bar $2 \mathrm{~cm}$ 
encircled the subterranean roots of the palm Serenoa repens, again indicating rhythmic extension.

Branching of AR of D. draco, so as to form a cluster, usually occurs with no indication of damage to the tip. Based on the AR studies of the mangrove Rhizophora mangle, it was suggested that branching without apparent injury occurs following prolonged quiescence of the root-tip (Gill and Tomlinson 1977). The AR of $D$. draco rather continue their growth following a dormant phase, in contrast to those of Ficus microcarpa, whose further growth is associated with ramification, so as to form a cluster, rather than an extension of existing AR (Pryor and Wei 2015).

\section{AR growth relative to weather conditions}

In the present study, the resuming of AR growth was associated with rainfall in November, which heralds the onset of the so-called wet months (XI-IV), whereas the cessation of growth was coincided with the dry months, which commence in May. Much of the AR framework was built between December and May, when AR length increased from $1 \mathrm{~cm}$ to $7.3 \mathrm{~cm}($ mean $=2.9 \pm 1.56 \mathrm{~cm})$. This coincided with maximum rainfall between December and February (Fig. 1). Most AR grew until May, whereupon symptoms of cessation of AR growth were observed, together with associated changes to pigmentation of the AR surface. Only eight of the studied AR continued elongating until August.

During the period of investigation, AR produced a single growth unit of mean length $3.1( \pm 1.59) \mathrm{cm}$. This closely resembled the $3.3 \mathrm{~cm}$ per year growth increment calculated for a single plant of $D$. draco growing on Tenerife by Krawczyszyn and Krawczyszyn (2014). However, retrospective analysis based on length measurements of all growth units of investigated AR indicated the mean growth unit length to be $3.54( \pm 1.8) \mathrm{cm}$, reaching a maximum $9.3 \mathrm{~cm}$. Therefore, the growth rate, and thus, growth unit length is inconsistent among AR (Fig. 3a). Furthermore, general observations of AR for a given individual plant of $D$. draco revealed that not all AR resumed the growth, but some remained resting (Fig. 2e-f), despite access to water. This would suggest that AR growth is not only dependent on seasonal changes, but is also determined by internal factors (Bellini et al. 2014).

Owing to the fact that temporal changes to AR length revealed a close relationship between AR elongation and precipitation, the number of growth units, when used in conjunction with meteorological data, makes it possible to estimate AR age. Figure 3a shows AR comprising 2-5 growth units. Therefore, it is reasonable to assume that the stress conditions that induced AR formation in these dragon trees lasts for at least 5 years. However,

a Total AR length VIII $2018 \quad$ [cm]
]

b

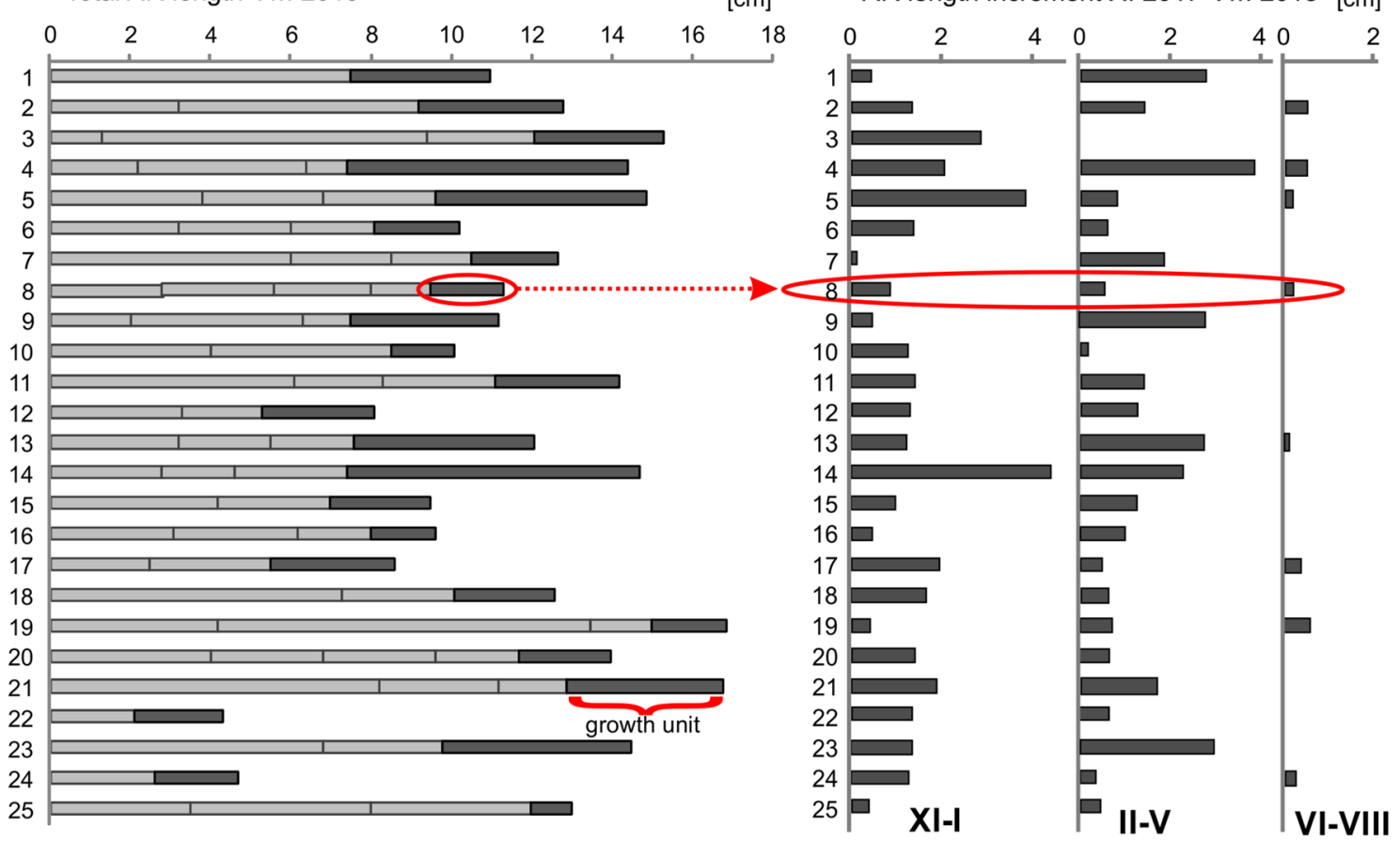

Fig. 3 AR growth characteristics. a Total length of 25 AR, together with the number of growth units and their length. The growth units, marked with dark gray on each AR, were formed during the period covered by the study. b AR length increment (marked with dark gray) measured in three periods of the year (Roman numerals refer to the months XI-I, II-V, VI-VIII). Most AR grew until May, with only eight of the studied AR (nos 2, 4, 5, 8, 13, 17, 19, 24) continuing to elongate until August 
determination of the exact age of AR seems not always to be possible, as AR are not uniformly active during elongation, i.e., some remain in the dormant phase, despite the wet season. What is more the retrospective estimation seems to be possible only several years back, because once the AR become older, they probably transform into thick longitudinal strands (as shown in Krawczyszyn and Krawczyszyn 2014), where growth units may not be apparent.

The periodic growth of trees growing in temperate zone is synchronized with seasonal constraints, and is easily distinguished at the morphological and anatomical levels (growth rings in wood due to the seasonal activity of vascular cambium). In the case of evergreen $D$. draco, no visual symptoms of its seasonal activity have so far been reported. At the anatomical level, differences in the mode of amphivasal bundle formation by a monocot cambium in the stem of D. draco has already been reported (JuraMorawiec 2015), and this may help determine the seasonal response of radial growth in this organ. However, no such studies have been conducted to date. This study is the first report of visual signs of seasonal growth of $D$. draco, which was found to be driven by rainfall totals. Modifications of the cells (most likely due to suberin deposition) in the periphery of AR, associated with the dormant phase, protect them from desiccation during dry periods.

AR have also been reported for other Dracaena spp., such as D. cinnabari from Socotra Island (Beyhl and Mies 2007), which is similar in form to D. draco (Marrero et al. 1998), but also for D. ellenbeckiana (Jura-Morawiec unpubl. data) from East Africa, which is a smaller tree or shrub, usually with several stems arising from a common base (Mwachala and Mbugua 2007). AR formation in Dracaena species appears to consist of a uniform pattern of response to specific stress conditions, and thus, further studies aimed at elucidating the function of AR would be of great interest.

To conclude, this study demonstrates the rhythmic growth of AR in evergreen $D$. draco. This is induced by wet conditions associated with rainfall. Rhythmic growth results in the formation of morphological markers on the surface of the AR which delimit successive growth units. An important application of the findings presented is that it allows estimate the age of these organs in $D$. draco. Furthermore, it makes it possible to estimate when the onset of stress occurred and, therefore, help to identify what caused it.

Author contribution statement JJ-M: study conception and design; collection of the measurements; analysis and interpretation of data; writing of the manuscript.
Acknowledgements The author thanks Dr. J. Caujapé-Castells, director of the Jardín Botánico Canario "Viera y Clavijo"-Unidad Asociada al CSIC of the Cabildo de Gran Canaria, for facilitating studies of dragon trees and help in obtaining meteorological data from the Agencia Estatal de Meteorología (AEMET). This study was carried out with support from the National Science Centre, Poland [grant number 2017/01/X/NZ8/00533].

\section{Compliance with ethical standards}

Conflict of interest The author declares that there is no conflict of interest.

Open Access This article is distributed under the terms of the Creative Commons Attribution 4.0 International License (http://creativeco mmons.org/licenses/by/4.0/), which permits unrestricted use, distribution, and reproduction in any medium, provided you give appropriate credit to the original author(s) and the source, provide a link to the Creative Commons license, and indicate if changes were made.

\section{References}

Adolt R, Pavlis J (2004) Age structure and growth of Dracaena cinnabari populations on Socotra. Trees 18:43-53

Adolt R, Habrova H, Madera P (2012) Crown age estimation of a monocotyledonous tree species Dracaena cinnabari using logistic regression. Trees 26:1287-1298

Barlow PW (1994) From cell to system: repetitive units of growth in the development of roots and shoots. In: Iqbal M (ed) Growth patterns in vascular plants. Dioscorides Press, Portland, pp $19-58$

Barthélémy D, Caraglio Y (2007) Plant architecture: a dynamic, multilevel and comprehensive approach to plant form, structure and ontogeny. Ann Bot 99:375-407

Bellini C, Pacurar DI, Perrone I (2014) Adventitious roots and lateral roots: similarities and differences. Ann Rev Plant Biol 65:639-666

Beyhl FE (1995) Two different growth forms of Dracaena draco L. (Monocotyledones: Liliales: Agavaceae). Bol Mus Munic Funchal 4:91-95

Beyhl FE (2001) Dragon-trees (Dracaena draco L.) with aberrant growth forms (Monocotyledons: Liliflorae: Agavaceae). Arquipélago. Life Mar Sci Suppl 2 (part B):101-103

Beyhl FE, Mies BA (2007) Die Wuchsformen des Drachenbaums (Dracaena cinnabari Balf. Fil.) auf der Insel Soqotra-growth forms of the Dragon tree (Dracaena cinnabari Balf. Fil.) of Soqotra island. Acta Biol Benrodis 14:55-66

Bos JJ (1984) Dracaena in west Africa. Agricultural University Wageningen Papers 84(1):v+1-126

Byström K (1960) Dracaena draco L. in the Cape Verde Islands. Acta Horti Gotob 23:179-214

Carlquist S (2012) Monocot xylem revisited: new information, new paradigms. Bot Rev 78:87-153

Cheadle VI (1937) Secondary growth by means of a thickening ring in certain monocotyledons. Bot Gaz 98:535-555

Fisher JB, Jayachandran K (2000) Root structure and arbuscular mycorrhizal colonization of the palm Serenoa repens under field conditions. In: Strokes A (ed) The supporting roots of trees and woody plants: form, function and physiology. Kluwer Academic Press, Dordrecht, pp 377-389

Fritts HC (1976) Tree rings and climate. Academic Press, London 
Gill AM, Tomlinson PB (1975) Aerial roots—an array of forms and functions. In: Torrey JG, Clarkson DT (eds) The development and function of roots. Academic Press, London, pp 237-260

Gill AM, Tomlinson PB (1977) Studies on the growth of red mangrove (Rhizophora mangle L.) 4. The adult root system. Biotropica 9:145-155

Hallé F, Martin R (1968) Etude de la croissance rythmique chez Hevea brasiliensis Mull. Arg (Euphorbiaceae-Crotonoidées). Adansonia 8:475-503

Hallé F, Oldeman RAA, Tomlinson PB (1978) Tropical trees and forests. Springer, Berlin

Jura-Morawiec J (2015) Formation of amphivasal vascular bundles in Dracaena draco stem in relation to rate of cambial activity. Trees 29:1493-1499

Krawczyszyn J, Krawczyszyn T (2014) Massive aerial roots affect growth and form of Dracaena draco. Trees 28:757-768

Krawczyszyn J, Krawczyszyn T (2016) Photomorphogenesis in Dracaena draco. Trees 30:647-664

Liu L, Fu X, Chen X (2016) The transpiration and moisture absorption characteristics of Ficus microcarpa (L.) aerial roots in the south of China. Pak J Bot 48:1473-1479

Lyons G (1974) In search of dragons or: the plant that roared. Cact Succ J 46:267-282

Mägdefrau K (1975) Das Alter der Drachenbäume auf Tenerife. Flora $164: 347-357$
Marrero A, Almeida RS, Gonzalez-Martin M (1998) A new species of the wild dragon tree, Dracaena (Dracaenaceae) from Gran Canaria and its taxonomic and biogeographic implications. Bot J Linn Soc 128:291-314

Mathews M, Wee ML, Ho K (1997) Growth and development of aerial roots of a tropical ornamental, Philodendron lacerum. J Hort Sci 72:27-34

Montoya-Alonso JA, Mellado I, Carretón E, Cabrera-Pedrero ED, Morchón R, Simón F (2010) Canine dirofilariosis caused by Dirofilaria immitis is a risk factor for the human population on the island of Gran Canaria, Canary Islands, Spain. Parasitol Res 107:1265-1269

Mwachala G, Mbugua PK (2007) Flora of Tropical East Africa-Dracaenaceae. Kew Publishing, Wojnowice

Pryor M, Wei L (2015) Aerial roots of Ficus microcarpa. Planting Futur 2015:76-84

Symon ED (1974) The growth of Dracaena draco-dragon's blood tree. J Arnold Arbor 55:51-58

Publisher's Note Springer Nature remains neutral with regard to jurisdictional claims in published maps and institutional affiliations. 